\title{
The Behavior of Online Consumer Opinions Case Tunisian Communities
}

\author{
Chiraz Rouissi $^{1} \&$ Fatma Letaief $^{2}$ \\ ${ }^{1}$ Jeddah University, KSA \\ ${ }^{2}$ Faculty of Economics and Management of Tunis, Tunisia \\ Correspondence: Chiraz Rouissi, Assistant Professor, Jeddah University, KSA.
}

Received: January 1, 2021

doi:10.5430/rwe.v12n1p364
Accepted: February 2, 2021

Online Published: February 22, 2021

\begin{abstract}
Online consumer opinions are an essential source of information on goods and services, with the framework of a Research Online Purchase Offline behavior. However, in a virtual environment, there are two types of consumers: opinion leaders and "lurkers" who do not participate in virtual communities. This research presents the results of a qualitative study on the obstacles and motivations for the participation of "lurkers" in Social Media and especially case of Facebook groups. It shows that even though "Lurkers" consider virtual communities as a public space that can triturate their confidentiality, in some cases they can manifest themselves and give rise to new behavior, which is "mobilizing behavior".
\end{abstract}

Background/Objectives: The main purpose of the research is to study and understand, through a preliminary qualitative study, the barriers, and motivations of passive users in a virtual community on Facebook. The theoretical scope of this research is based on a lack of theoretical work, addressing the barriers and motivations to convert a Lurker into an Opinion Leader (Vasic, N \& al. 2019) in the context of Research Online Purchase Offline "ROPO" behavior.

Methods/Statistical. Methodological tools of the research methods were qualitative, a survey based on an interview is conducted with a sample of the relevant population, namely, subsidiaries of Tunisian communities' groups. Given the exploratory nature of this study, the choice of a qualitative analysis seems appropriate. The method of data collection through semi-structured interviews

Findings: This study examined the literature on online behaviors and aimed to provide a comprehensive understanding of Lurkers' behavior context through a qualitative exploratory study. The qualitative study shows that the "Lurkers" brakes are mainly around the fact that they want to protect their private lives by leaving as little data as possible so as not to receive abusive requests for additions, they try to keep some perspective to avoid any kind of conflict with strangers when it comes to different opinions.

Improvements: This study can provide input at the managerial level, especially for creators of virtual communities. In practice, brands develop virtual communities intending to improve the "consumer-brand" relationship as well as the relationship between consumers. The obstacles for Lurkers to participate can give brands a clear idea of the need to develop engagement platforms. More specifically, the brand must give more opportunities to the lurkers to give their opinions so that they can participate without fear.

Keywords: posters, consumer empowerment, opinions behavior, behavior consumer

\section{Introduction}

Today, many virtual communities ensure that they have the right policies and the right content, to attract more Internet users and to be able to grow almost organically (Vasic, $\mathrm{N}$ and al. 2019). However, many users rely on these communities to obtain useful information instead of offline sources of information (Chou, Lin \& Huang, 2016). Since 2013, more than $95 \%$ of consumers have prepared their purchases on the internet through virtual communities, before going to the store. Wikipedia constitutes one of the 15 most popular websites as ranked by Alexa, as of January 2021. Featuring no advertisements, it is introduced by the Wikimedia Foundation, it constitutes an American non-profit organization supported principally through donations. In January 2020, there are 7,550,000 Facebook users in Tunisia (digital discovery, 2020). The number of internet users in Tunisia increased by 48 thousand (+0.6\%) between 2019 and 2020. Besides, Internet penetration in Tunisia stood at 64\% in January 2020. In a recent study of 
the content of four separate digital health social networks, researchers reported that $1 \%$ of the most active users created an average of $73.6 \%$ of posts, the next $9 \%$ averaging $24.7 \%$ of publications, and the remaining $90 \%$ having averaged $1.7 \%$ of publications (Van. Mierlo and al, 2019). Each participant in virtual communities, active or silent, reads more messages than they have written (Hanif. H 2016).

Unlike opinion leaders who always comment on and share social media posts, "lurkers" make up a very special community on social media. They are connected, attentive to the content they consult but never or very rarely appears. One potential problem that hinders the growth of a virtual community is the lack of participation of its members in the publication of content. Indeed, even with the appropriate technology, there are often many "lurkers" who do not participate (Van Mierlo and al, 2019).

This apparent passivity then represents a significant communication issue. This research tries to answer the question: "How do Lurkers identify themselves to contribute to a virtual community Online Purchase Offline"?

This research constitutes a part of the general framework of a better understanding of identifying "lurkers" to participate in virtual communities in a ROPO context. We try to examine the conversion of a Lurker to an Opinion Leader while basing on their brakes and their motivations to participate in virtual communities. The main objective is to identify and understand, through a preliminary qualitative study, the barriers, and motivations of passive users in a virtual community on Facebook. The theoretical space of this research is based on a lack of theoretical work, addressing the barriers and motivations to convert a Lurker into an Opinion Leader (Bishop, 2011) in the context of Research Online Purchase Offline behavior. On a managerial level, this research could help managers find management solutions for their Facebook pages or Facebook groups according to their themes. In other words, it helps to understand the brakes that block Lurkers from interacting on their Facebook pages. In the first part of this article, we will focus on the literature relating to online social interactions. In the second part, we will discuss the results of the qualitative study conducted. In a conclusion, some avenues of research will be developed.

\section{Literature Review}

\subsection{Theoretical Foundation}

Based on a theoretical foundation, several typologies of internet users have been identified by Valverde-B \& al. 2020). Indeed, Mathwick (2002) states that there are four types of users on the Internet namely: Lurkers (the most inactive group), personal connectors, socialization agents, and members of the years-old actional community. Whereas Li and Bernoff (2008) show that there are six users on the web: the inactive, the spectators, the sociable, the collectors, the critics, and the creators. The work of Pagani and Mirabello (2011) combined with that of Li \& Bernoff (2008) shows two types of users: active users and passive users of social media. Active users of social media are creators, critics, collectors, and carpenters, who are similar in concept to opinion leaders and who have a higher level of engagement on the web. Passive users of social media are spectators, whose concept is similar in the level of engagement of users who observe and consume information without them reacting with other consumers on the web as identified by Muntinga et al. (2011). According to authors Christy Cheung, Xiao et. Liu (2012), there are two types of users: opinion-based users and behavior-based users. The first type of user is represented by electronic word of mouth in the marketing literature (Eigenraam, A \& al 2018). While the second type concerns lurkers in psychology and economics literature ((Eigenraam, A \& al 2018).

Social exchange theory is a major theoretical lens for justifying employee behaviors and relationships in the work environment. Since it appeared in the 1920s, social exchange theory has associated several disciplines and has been applied to diverse studies fields (Cropanzano \& Mitchell, 2005), such as networks (Faraj \& Johnson, 2011; Wong \& Boh, 2010), online communities (Liang, Liu, \& Wu, 2008; Wasko \& Faraj, 2005), and leadership (Liden, Sparrowe, \& Wayne, 1997).

\subsubsection{The Behaviors of Online Consumers}

According to Lushed. G (2005) defines a lurker as the term "lurker" 'is often used to describe someone who observes what is going on but does not participate or remains silent, and is thus associated with observation, silence, inactivity/passivity, invisibility, or bystander behavior'. They are described as a passive or in-visible, hard to reach or hard to involve the population in online communities, nonpublic participants, inactive and silent, even though they can make up more than $90 \%$ of the online group". The act of "lurking" is a vicarious learning process, during which "lurkers" can benefit cognitively and socially based on observation of the experience of others ((Eigenraam, A\& al 2018). To understand why this "silent majority" does not share publications, Nonnecke \& Preece (2004) jointly conducted a series of research, they found that "lurking" is the result of a complex set of actions, justifications, and contexts. This definition describes two characteristics of "lurkers" which are in particular; rare posting of messages 
and reading messages regularly, but it does not set quantitative standards about lurkers. Previous studies have identified lurkers in different ways namely, members who have never posted a message in a virtual community, members who have only once shared messages for a long time (Golder \& Donath, 2004 ,Neelen \& Fetter 2010; Nonnecke \& al., 2006), members who did not contribute to the community during three months (Nonnecke \& Preece, 2000), members who initially only share three or more posts, or members who have never posted in the past four months (Ganley \& Moser \& Groenewegen, 2012). Nonnecke \& Preece, (2001) state that large parts of members of virtual communities are lurkers rather than opinion leaders. Over $90 \%$ of members of some large online groups such as MSN and AOL communities were lurkers (Katz, 1998) Operationally, researchers often define this concept as " no messages being sent in a three-month (Nonnecke \& Preece, 2001) and " visits regular to the virtual community with a reluctance or a very rare sharing of information (Rafael and al, 2004). Although some researchers have criticized that "lurkers" are free riders, that is, no-contribution in information sharing (Smith \& Kollock, 1999), other researchers have argued that the behavior of "lurkers" is normal at most of the population (Nonnecke \& Preece, 2000).

Besides, recent studies on virtual communities found no significant difference in valuation between lurkers and posters in spreading word-of mouth (Mousavi and al 2017), although lurkers and posters incorporate different factors when determining future behavior's and intentions (Lai and Chen 2014; Chen et al. 2019). This study recommends the need to pinpoint their distinct mindsets towards continuance intention, a line of research that has been neglected. Taken together, it would be enlightening to go beyond these theoretical perspectives to understand both participation and browsing in virtual communities. (Fang \& al. 2019)

\subsubsection{Opinion Advisers}

Opinion leaders constitute a group of people who are interested in product areas and who make the effort to submit media sources and are approved by opinion leaders to give sound advice (Litvine \& al, 2008). On social media, opinion leaders play different roles due to their motivations and interests. Indeed, opinion leaders can be classified as information transmitters and information donors at the same time (Sun \& Youn, Wu \& Kuntaraporn, 2006), Usually opinion leaders have more experiences or knowledge of a certain category of products through direct exposure or by seeking information about a certain product and are more likely to discuss these products with others (Myers \& Robertson, 1972). Opinion leaders are more likely to display innovative behavior than to demand opinions, and thus tend to show a higher level of engagement with the product (Henderson \& Lyon, 2005). They also found that opinion leaders represent social leadership and have active social involvement, which empowers them to influence others, rather than being influenced. Anyone can be a thought leader by giving their opinion to close friends, family members, parents, acquaintances, or even strangers (Litvine \& al., 2008),

\subsection{Online Interactions}

A virtual community is a website on which its users can post or edit content (Bishop, 2009), and these users must cross the barriers that prevent them from hiding and not sharing posts (Kim \& al. Powazek, 2002). Community development is becoming an important component of Internet commerce, understanding online interactions will become an essential part of doing business (Nonnecke \& Preece, 2000). The motivations for "lurkers" should not be ignored even if the latter is invisible to the community (Sproull \& al 2005). First created by Ismail. E (2016), "Communities of practice are groups of people who share a concern, set of problems or passion for a topic and who deepen their knowledge and expertise in a specific area in interacting continuously "(Wenger \& al, 2002). Not all virtual communities are communities of practice. For a community to be a community of practice, its members must come together around a common interest or area, they must participate in common activities and discussions that would strengthen their community and constitute a common accumulation of resources. As a result of social interactions, community members can find solutions to the problems they face, both short and long term, and develop new solutions related to the problems. Communities of practice are not simply communities that deal with issues. They are also communities in which members create lasting values that match the long-term goals of the community. Besides, community members contribute to the development of these communities by building a database, sharing their knowledge, skills, and experiences, and monitoring progress in their fields (Liu, C \& al 2020). Communities of practice help their members to achieve concrete or abstract gains, in particular by allowing them to improve their knowledge or to access information more quickly, the reinforcement of the feeling of confidence, or the increased capacity to design a new product. However, the greatest value that a community of practice provides to its members is comprised of abstract results. Examples include friendship between members, a sense of belonging, professional confidence, and a heightened sense of solidarity (Liu, C \& al 2020).

These dynamics of online social interactions in a virtual community are summarized. 


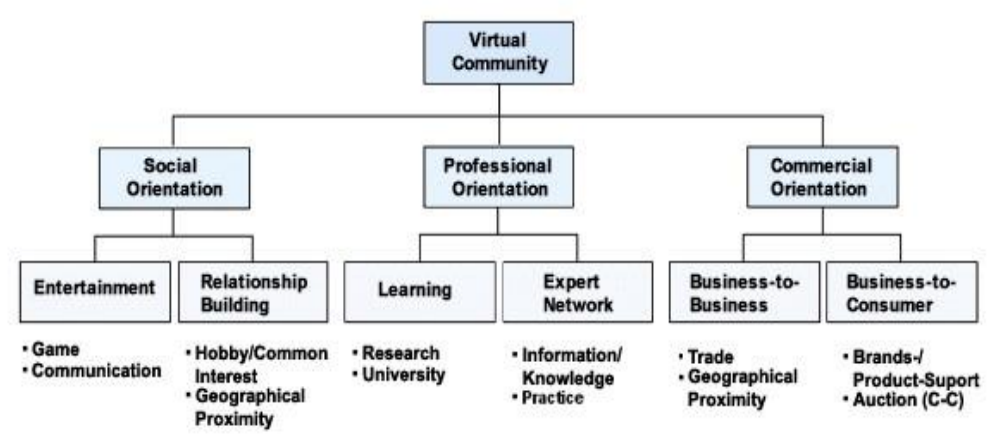

Figure 1. Identifying opinion of virtual communities

Source: Inspired from (Markus, 2002)

\section{Methodology}

This research used the qualitative method, given the exploratory nature of this study, the choice of a qualitative analysis seems appropriate. The method of data collection through semi-structured interviews was favored.

The objectives of the qualitative study are based on two main parts: The first part is to understand, interpret and explain the factors for converting a Lurker into an Opinion Leader. The second part consists of proposing a preliminary model of the antecedents and consequences of the exploitation of the opinions of other consumers by Lurkers in a "ROPO" context. In writing the interview guide, we covered a list of topics as follows: Research Online Shopping Behavior, Purchase Offline Online Social Interactions; Consumer Empowerment; Direct consumer experience; Customer Engagement Behavior. Within the framework of this study, we succeeded in reaching an acceptable saturation with a sample of 14 interviewees. The average interview time is 35 minutes. Our sample is homogeneous, made up of different Internet users who subscribe to different virtual communities, on the assumption that many interviewees are both "lurkers" and "opinion leaders". The interviews were designed to get as broad a picture as possible. Given the relatively high incidence of "lurkers" reported by Guo \& Wu, H. (2018), it was assumed that most participants would likely be "lurkers".

\section{Results and Discussion}

\subsection{Data Analysis and Processing}

After carefully transcribing all the data collected from the respondents during the interviews, we conducted a thematic content analysis. We have divided the verbatim into themes and sub-themes, through the literature review and our intuitions. We started then, with the sentences, the ideas, and the keywords which can help us to bring out the big topics. We used NVIVO 12 software to process the data collected. Also, we did the coding of the corpus and discussed our various coding with two assistant Professors.

\subsection{Discussion of the Results}

In response to the thematic analysis of the content of the various interviews, we were able to identify the variables explaining the identification of "lurkers" to participate in virtual communities in a ROPO context. We present the results of the analysis Inter-site and the matrix encoding query.

We began with an overview of how consumers develop, adapt, and use decision-making strategies. Content analysis of all the verbatim from the 14 interviews left us with a sense of the importance attached to the use of the Internet in general and the opinions of consumers that flow from virtual communities as a preliminary step in the purchasing decision process. Below we present the Inter-Site matrix encoding request for the Research Online, Purchase Offline ROPO behavior of the consumer. The first axis groups all the interviews with the different internet users subscribing to different virtual communities and the second axis groups the number of encoding references for the consumer's ROPO behavior. The analysis result presents the level of behavior Research Online, Purchase Offline of the consumer in each interview. This level is determined by counting the number of encoded references grouped in the "Research Online Behavior, Purchase Offline of consumer" code for each interview. 
Table 1. Analysis of consumer behavior research online, purchase offline

\begin{tabular}{lll}
\hline & A : Information Research Offline & B : Information Research Online \\
\hline Interview 1 & 1 & 12 \\
\hline Interview 2 & 3 & 11 \\
\hline Interview 3 & 3 & 5 \\
\hline Interview 4 & 5 & 8 \\
\hline Interview 5 & 2 & 11 \\
\hline Interview 6 & 1 & 5 \\
\hline Interview 7 & 1 & 4 \\
\hline Interview 8 & 2 & 14 \\
\hline Interview 9 & 1 & 13 \\
\hline Interview 10 & 3 & 6 \\
\hline Interview 11 & 10 & 5 \\
\hline Interview 12 & 11 & 5 \\
\hline Interview 13 & 5 & 6 \\
\hline Interview 14 & 4 & 8 \\
\hline
\end{tabular}

In the light of these illustrations, most of the interviewees affirm that their purchasing procedures always start on the internet before eventually being finalized in a physical store. This result takes on its full meaning according to CCM Benchmark Institute, which states that this behavior is highly widespread. Thus, according to the literature, the online shopping landscape is gradually changing in terms of the types of products being bought online. Generally, consumers' organized online purchases suggested a year over year increase for best product categories $85 \%$ of Internet users often or systematically obtain information on the Internet before buying in a physical store, particularly those more traditionally sold in shops (Jung, B and al, 2020).

Thus, most respondents use the Internet to find out about a product before going to a physical store to buy it "... before buying a product, I always synchronize my thinking with the opinions of consumers. I start by consulting the opinions of my peers and those of members of my network, to assess the quality of the product and/or the service that I foresee to buy "(interview 2)," ... thanks to the internet that a great openness to the world can be possible, information that can be obtained immediately. It seems essential to me today "(interview 8)," I always have the instinct to do my research on Facebook groups or brand pages on Facebook. I put in a keyword and start my search, and it's much easier to find what I'm looking for "(interview 1).

\subsubsection{Social Web Site Groups}

The informative role of the Internet provides access to many sources of information namely the sources of information from consumers in Facebook groups. Almost mentioned by the majority of interviewees, online reviews have become an important source of information for consumers (Pan et al., 2007), serve to reduce risks, guarantee lower prices, and obtain information easily. (Goldsmith and Horowitz, 2006) "Every day, we find dissatisfied customers after having bought following the so-called advice of sellers. Frankly, I am still skeptical of their claims. ... So today, I go more to Facebook groups, where people share their feedback, give their opinions, and they are not paying for it" (Interview 8). However, the rapid spread of Internet access has provided a new wave of virtual communities, many users rely on these communities to obtain useful information instead of offline sources of information. From the Inter-Site analysis of virtual communities, we can see that the Facebook group "We ate for you" was highlighted by all the interviewees.

\subsubsection{Consumer Empowerment}

This part presents the Inter-Site matrix encoding request related to the consumer empowerment of lurkers. The first axis groups all the interviews with the different Internet users subscribed to different virtual communities and the second axis groups the number of encoding references for the consumer empowerment of lurkers. The analysis result 
presents the level of consumer empowerment of the lurkers in each interview. This level is determined by counting the number of encoding references grouped in the "Consumer empowerment lurkers" code relating to each interview.

Table 2. Results of analysis relating to consumer empowerment lurkers

\begin{tabular}{|c|c|c|c|c|c|c|}
\hline & $\begin{array}{l}\text { A: } \\
\text { Empowerment }\end{array}$ & $\begin{array}{l}\text { B: Action } \\
\text { collective }\end{array}$ & $\begin{array}{l}\text { C: Relation Inter } \\
\text { Personnel }\end{array}$ & D: Competence & E: Contrôle & F: Self efficacy \\
\hline Interview 1 & 1 & 7 & 15 & 5 & 5 & 12 \\
\hline Interview 2 & 2 & 0 & 1 & 2 & 2 & 0 \\
\hline Interview 3 & 2 & 0 & 0 & 4 & 4 & 0 \\
\hline Interview 4 & 4 & 2 & 2 & 7 & 7 & 1 \\
\hline Interview 5 & 1 & 0 & 1 & 4 & 4 & 4 \\
\hline Interview 6 & 0 & 1 & 1 & 4 & 4 & 6 \\
\hline Interview 7 & 1 & 0 & 0 & 3 & 3 & 0 \\
\hline Interview 8 & 1 & 3 & 4 & 7 & 7 & 8 \\
\hline Interview 9 & 3 & 5 & 5 & 7 & 7 & 6 \\
\hline Interview10 & 0 & 1 & 1 & 0 & 0 & 0 \\
\hline Interview 11 & 0 & 1 & 2 & 0 & 0 & 4 \\
\hline Interview 12 & 1 & 5 & 6 & 2 & 8 & 1 \\
\hline Interview 13 & 0 & 6 & 4 & 3 & 6 & 7 \\
\hline Interview 14 & 2 & 5 & 3 & 6 & 5 & 5 \\
\hline
\end{tabular}

Considering these illustrations, most interviewees say that their buying procedures always start on the internet before they are eventually finalized in a physical store. This result makes perfect sense according to the CCM Benchmark Institute, which states that this behavior is widely used. According to the literature, $67 \%$ of Internet users often or systematically find out more about the Internet before buying in a physical store (Jung, B and al, 2020).

For example, most respondents use the internet to find out about a product before going to buy it in a physical store "... before buying a product, I always synchronize my focus on consumer reviews. I begin by consulting the opinions of my peers and members of my network, to evaluate the quality of the product and/or the service I plan to buy", "... thanks to the internet that presents a great opening to the world, information that we can have right away. It seems essential today" (interview 8), "I always have the reflex to do my research on Facebook groups or brand pages on Facebook. I put a keyword in and start searching, and it's much easier to find the answer you're looking for" (interview 1). Also, I do not dismiss passive content consumption (Interview 13).

\subsubsection{Informational Role of the Internet}

The informational role of the Internet provides access to many sources of information, namely sources of information from consumers in Facebook groups. Almost by most interviewees, online reviews have become important sources of information for consumers (Pan \& al., 2007), used to reduce risk, ensure lower prices, and obtain information easily (Goldsmith \& Horowitz, 2006). ".. Every day, we find customers dissatisfied after buying following the so-called advice of the sellers. Frankly, I am still skeptical of what they say. ..... So today I go more to Facebook groups, where people tell their feedback on experiences, give their opinions, and they don't pay for it" (interview 8). In any case, the rapid spread of Internet access has provided a new wave of virtual communities, many users rely on these communities to obtain useful information instead of offline sources of information. From the Inter-Site analysis of virtual communities, we can see that the Facebook group "We ate for you" was highlighted by all the interviewees.

\subsubsection{Consumer Empowerment}

Below is the Inter-Site matrix encoding request for the consumer empowerment of lurkers. The first axis brings together all the interviews with the different Internet users who subscribe to different virtual communities and the second axis includes the number of encoding references for the consumer empowerment of lurkers. The analysis 
result shows the level of consumer empowerment of the lurkers in each interview. This level is determined by counting the number of encoding references grouped in the "Consumer empowerment lurkers" node for each interview.

Table 3. Result of the Inter-site analysis on consumer empowerment lurkers

\begin{tabular}{|c|c|c|c|c|c|c|}
\hline & $\begin{array}{l}\text { A: mpowerment } \\
\text { Comportemental }\end{array}$ & $\begin{array}{l}\text { B: Collective } \\
\text { Action }\end{array}$ & $\begin{array}{l}\text { C: Inter } \\
\text { Personnel } \\
\text { Relation }\end{array}$ & D: ompetence & E: Control & $\begin{array}{l}\text { F: Self } \\
\text { efficacy }\end{array}$ \\
\hline Interview 1 & 1 & 7 & 15 & 5 & 5 & 12 \\
\hline Interview 2 & 2 & 0 & 1 & 2 & 2 & 0 \\
\hline Interview 3 & 2 & 0 & 0 & 4 & 4 & 0 \\
\hline Interview 4 & 4 & 2 & 2 & 7 & 7 & 1 \\
\hline Interview 5 & 1 & 0 & 1 & 4 & 4 & 4 \\
\hline Interview 6 & 0 & 1 & 1 & 4 & 4 & 6 \\
\hline Interview 7 & 1 & 0 & 0 & 3 & 3 & 0 \\
\hline Interview 8 & 1 & 3 & 4 & 7 & 7 & 8 \\
\hline Interview 9 & 3 & 5 & 5 & 7 & 7 & 6 \\
\hline Interview 10 & 0 & 1 & 1 & 0 & 0 & 0 \\
\hline Interview 11 & 0 & 1 & 2 & 0 & 0 & 4 \\
\hline Interview 12 & 3 & 6 & 2 & 5 & 3 & 0 \\
\hline Interview 13 & 1 & 2 & 6 & 3 & 4 & 1 \\
\hline Interview 14 & 0 & 1 & 3 & 1 & 0 & 4 \\
\hline
\end{tabular}

Based on these illustrations we can reveal that consumer psychological empowerment includes three components: intra-personal empowerment, interactive empowerment, and behavioral empowerment. Intrapersonal empowerment refers to how individuals perceive themselves and their ability to influence others, as well as social and political systems (Jung, Ki B, Kang, Seung-Wan, Choi, Suk B. 2020). It has three dimensions: control, personal effectiveness, and perceived competence (Jung, Ki B, Kang, Seung-Wan, Choi, Suk B. 2020). The control aspect refers to beliefs about a person's ability to exert influence in various contexts; The personal efficiency aspect refers to the self-assessment of the ability to perform certain tasks, while the perceived competency aspect refers to perceptions of one's ability to perform a job or task well (Jung, Ki B, Kang, Seung-Wan, Choi, Suk B. 2020). Interactional empowerment refers to the intellectual understanding of the social environment and the knowledge and resources needed to produce change and the sharing of information and knowledge and fostering cross - cultural dialogue can be an elevating experience for both the "powerful" and the "powerless". (Siebenhüner, B., \& al. 2010) It has two dimensions: collective action and interpersonal relationships. Specifically, collective action refers to an understanding of the collective mechanism required and the group's power to create change. Interpersonal relationships deal with understanding the intimate interpersonal relationships needed to develop social power (Siebenhüner, B., \& al. 2010). Finally, behavioral empowerment refers to responsible actions that may influence outcomes (Jung, Ki and al. 2020.). This is achieved through participation activities and community organizations such as political groups, self-help groups, religious groups, or service organizations, or helping others deal with problems (Jung, Ki and al. 2020.).

Social media has created a vast connection within virtual communities with a collaborative and participatory culture (Henderson and Bowley, 2010). They encourage media users to discuss, debate and collaborate with each other as thousands of others observe, listen and learn (McConnell \& Huba, 2007). The majority of respondents agree that when they visit a Facebook group, they always start by reading online comments to save time and make better purchasing decisions. They read and observe the experiences of others in order to reduce risks, guarantee lower prices, and get information easily before the act of purchase, "... It can be used to collect ideas and always be up to date. Knowing the experiences of others can only enrich me.... I find answers to which I easily seek without any 
effort on my part. and this is valid for all categories of products: clothing, food, appliances ... Basically it can only be an information network, and a way to be aware of what's new" (interview 9), "Sometimes I find useful contacts that can serve me later" (interview 1), "These groups look like a guide that serves to guide you and offer you multiple plan " (interview 7). Indeed, these statements reinforce the literature that states that learning about the social environment leads to the development of decision-making and the skills needed to solve problems and actively participate in their environment (Jung, Ki and al (2020). On the other hand, respondents were found to be very aware of their influence on other online consumers and the collective power they can exert on businesses. This makes sense in the literature which states that that the intra-personal component of empowerment refers to how individuals think about themselves and their ability to influence others (Jung, Ki and al (2020). What strategies should be used to ensure that the use of the Internet promotes solidarity between people who used the same web group? "I think when we exchange ideas in plenary." (Interview 13). Indeed, the most active users, who are often opinion leaders on the virtual sphere, can influence the decisions of others ( $\mathrm{Li}$ and Stacks, 2014). One example is these statements, "I can be influenced, and I can even be excited to buy the product they are talking about. Sometimes I buy a product based on recommendations read on Facebook" (interview 11), "Yes of course they can influence me, for example, if I find 200 negative comments about a product in front of 150 positive comments, I will immediately cancel the idea of buying one and vice versa" (interview 1).

\subsubsection{Online Social Interactions}

Considering the Inter-Site analysis of social interaction, we find that there are two types of users of virtual communities: lurkers and opinion leaders.

Referring to the lurkers, the unanimity of respondent's state that Internet users who comment recklessly within virtual communities represent a very passive community. They are connected, attentive to the content they consult but which hardly react on the web. They hardly like it. They hardly publish. They hardly comment. And yet, they are present and receptive to the content shared by other consumers. "I don't react with a "like" or a comment to avoid notifications due to this comment. I don't like notifications; I like not seeing my profile circulating within other people's comments. I always want to see without reacting" (interview 1), "... Not once, I can't find any pleasure to share in social networks. I don't want to spread my activities on social media. I find it stupid to share every time what I ate, or I went, what did I pay... etc. "... and as I've explained to you before, I'm one who observes everything that happens on the band but doesn't share anything" (interview 5), ". No, impossible, I do not want to spread my experiences on social networks ... I want it to be perfect, well-argued, well structured, since it will be exposed in front of several people in the group, and it will take me a lot of time, so I am lazy, I revoke to write" (interview 11) and I don't have time to answer (Interview 14). So, based on opinion leaders, respondents say they make comments, make likes, and share publications.

\subsubsection{Experience of the Customer}

Based on the Inter-Site analysis of the direct experience of opinion-leading consumers and lurkers with the product, most respondents recommend that they always make comparisons between what they have learned about the product via Facebook groups and their own experiences, "Obviously, I based myself on the reviews read, so I'll see if I did well by following their recommendations or not" (interview 8). Nevertheless, the relationship between consumer satisfaction when purchasing the product and post-purchase behavior differs according to the different levels of satisfaction, i.e., its low and high levels. Subordinated to indirect experiences with the product, consumer satisfaction can be enhanced by direct experience with the product (Brakus et al., 2009; Frow and Payne, 2007).

\subsubsection{Customer Engagement Behavior}

Below is the Inter-Site matrix encoding query for customer engagement behavior. The first axis brings together all the interviews with the different Internet users who subscribe to different virtual communities and the second axis includes the number of encoding references for customer engagement behavior. The analysis result shows the level of customer engagement behavior in each interview. This level is determined by counting the number of encoding references grouped in the "customer engagement behavior" code for each interview. 
Table 4. Results of the analysis of the customer engagement behavior

\begin{tabular}{|c|c|c|c|c|}
\hline & $\begin{array}{l}\text { A: Increasing } \\
\text { Behavior }\end{array}$ & $\begin{array}{l}\text { B: Co-development } \\
\text { behavior }\end{array}$ & C: Influence behavior & $\begin{array}{l}\text { D: Mobilizing } \\
\text { behavior }\end{array}$ \\
\hline Interview 1 & 0 & 0 & 0 & 1 \\
\hline Interview 2 & 1 & 1 & 1 & 2 \\
\hline Interview 3 & 1 & 1 & 1 & 0 \\
\hline Interview 4 & 0 & 0 & 0 & 2 \\
\hline Interview 5 & 0 & 0 & 0 & 0 \\
\hline Interview 6 & 0 & 0 & 1 & 0 \\
\hline Interview 7 & 0 & 0 & 0 & 0 \\
\hline Interview 8 & 1 & 0 & 2 & 0 \\
\hline Interview 9 & 0 & 0 & 0 & 0 \\
\hline Interview 10 & 0 & 0 & 0 & 2 \\
\hline Interview 11 & 0 & 0 & 0 & 2 \\
\hline Interview 12 & 1 & 0 & 0 & 1 \\
\hline Interview 13 & 0 & 1 & 1 & 0 \\
\hline Interview 14 & 0 & 0 & 0 & 2 \\
\hline
\end{tabular}

Based on the illustrations, there are different types of customer engagement behavior, namely co-developer behavior, influence behavior, increasing behavior, and mobilizing behavior. The behavior of co-developers is defined as customer contributions in the form of resources such as knowledge, skills, and time, to facilitate the development of the target company's offering (Busalim, A \& al. 2019). Influence behavior refers to client contributions in the form of resources such as knowledge, experience, and time, to affect the perceptions, preferences, or knowledge of other actors regarding the target company (Busalim, A \& al. 2019). Increasing behavior is defined as client contributions to resources such as knowledge, skills, labor, and the time needed to increase and complete the target company's offer beyond what is fundamental to the transaction ((Busalim, A \& al. 2019).

And the mobilizing behavior that occurs when engaged customers go beyond simply influencing the perceptions of other stakeholders to generate real action in favor of a focused company. Mobilizing behavior is defined as the contributions of clients in resources, such as relationships and time, to mobilize the actions of other stakeholders in favor of the target company (Busalim, A \& al. 2019). It is perhaps better understood about a socially responsible action on the part of the client, where other actors are invited to behave in a certain way towards a focal organization. This can be done either by "boycotts" or by "purchases" of certain products (Paek and Nelson, 2009).

In our research, we have focused on the motivations that can convert a "lurker" into an "Opinion Leaders." Note that most respondents are "Lurkers," saying they will never react positively or negatively as a result of a direct experience with the product. Based on the verbatims of our study, we noted that 12 respondents reported sharing a publication following a poor experience with the product. Therefore, a new type of behavior that was born in the «lurker», that of mobilizing behavior, which occurs when it goes beyond simply influencing other consumers' perceptions through their opinions to elicit real action in favor of or against the product or brand. The main verbatims collected relating to this new behavior of the "Lurkers" are: "... so I was upset and I did not know what to do, I decided to write a status on several groups, mentioning the name of the sign while telling my misadventure and ... the only thing I was able to relieve was the fact, of shared a call for a boycott against this brand so that it does not repeat with another person " (interview 8), "I also shared my experience, compared to a Tunisian brand with which I had a bad experience ... when I have time and when I meet a publication from the brand, I make the same comment for people to boycott this brand... I decided to boycott this brand and encourage people to boycott it" (interview 10), "... it happened to me to share before a post in a Facebook page of a cosmetic brand ... I used a fake profile to do it and call for a boycott" (interview 11). I could use the Internet to contribute to youth engagement, mobilization, and solidarity (Interview 12). "I found that the Internet should be used or integrated in connection with our solidarity committee". (Interview 14). To this end, Pisani and Piotet address the concept of the «web actor», the one that is no longer passive in the face of 
information and who now participates: the users of the web today offer services, exchange information, comment, get involved, participate. They produce most of the content of the web. These Internet users in full mutation no longer just navigate, surf. They act." (Pisani \& Piotet, 2008, p.2)

\section{Conclusion}

This study examined the literature on online behaviors and aimed to provide a comprehensive understanding of Lurkers' behavior in a Research Online Purchase Offline, context through a qualitative exploratory study. The qualitative research shows that the "Lurkers" brakes are mainly around the fact that they want to protect their private lives by leaving as little data as possible so as not to receive abusive requests for additions, they try to keep some perspective to avoid any kind of conflict with strangers when it comes to different opinions. In the end, it was noticed in several interviewees, that a "lurker" can be converted into a leader of opinion, and this through a mobilizing behavior that calls to boycott certain brands following extreme misadventures with the product.

\section{Theoretical Implications}

From a theoretical point of view, our study contributes to the enrichment of research on the behavior of Lurkers in the dynamics of virtual communities. Besides, it provides an opportunity to propose a conceptual model of the history and consequences of Lurkers' use of other consumer reviews in a Research Online Purchase Offline context.

\section{Managerial Implications}

This study can provide input at the managerial level, especially for creators of virtual communities. In practice, brands develop virtual communities intending to improve the "consumer-brand" relationship as well as the relationship between consumers. The obstacles for Lurkers to participate can give brands a clear idea of the need to develop engagement platforms. More specifically, the brand must give more opportunities to the lurkers to give their opinions so that they can participate without fear.

\section{Future Limits and Paths of Research}

The limit of this study lies in the use of a single method of investigation, that of maintenance. It would be interesting to extend this study with a quantitative experiment to validate the main result of this study.

If we consider that lurking could be a personality trait like shyness that can be valuable to incredibly busy communities, and is authorized by many communities, then better tools are necessary to support useful lurking. Such tools would be valuable to posters too, many, if not most of whom, begin their existence in a new community as a lurker until they have realized the rules and norms of the community.

It is obvious that lurker influences communities at different stages of progress and how lurking can be managed appropriately are particularly crucial research issues for the future.

\section{References}

Betura, A. (1977). Social Learning Theory, in International encyclopedia of psychiatry, psychology, psychoanalysis, et neurology. New York: Van Nostret Reinhold.

Bikhchandani, S., Hirshleifer, D., \& Welch, I. (1988). Learning from the behavior of others: Conformity, fads, et informational cascades. Journal of Economic Perspectives, 12(3), 151-170. https://doi.org/10.1257/jep.12.3.151

Busalim, A. H., Che Hussin, A. R., \& Iahad, N. A. (2019). Factors influencing customer engagement in social commerce websites: a systematic literature review. Journal of Theoretical and Applied Electronic Commerce Research, 14(2), 1-14. https://doi.org/10.4067/s0718-18762019000200102

Chou, E.-Y., Lin, Ch.-Y., \& Huang, H.-C. (2016). Fairness and devotion go far: Integrating online justice and value co-creation in virtual communities. International Journal of Information Management, 36(1), 60-72. https://doi.org/10.1016/j.ijinfomgt.2015.09.009

Christy, M. K. C., Xiao, B., \& Liu, I. (2012). The impact of observational learning et electronic word of mouth on consumer purchase decisions: the moderating role of consumer expertise et consumer involvement. 45th Hawaii International Conference on System Sciences (pp. 3228-3237). https://doi.org/10.1109/HICSS.2012.570

Cropanzano, R., \& Mitchell, M. S. (2005). Social exchange theory: An interdisciplinary review. Journal of Management, 31(6), 874-900. https://doi.org/10.1177/0149206305279602

Eigenraam, A., Eelen, J., Lin, A., \& Verlegh, P. (2018). A consumer-based taxonomy of digital customer

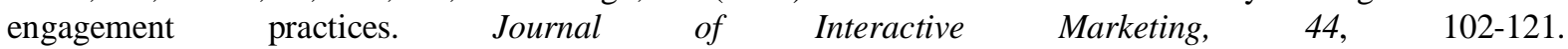
https://doi.org/10.1016/j.intmar.2018.07.002 
Erken, I. (2016). The influence of electronic word of mouth in social media on consumers' purchase intentions. Brunel University.

Fang, Y.-H., Li, C.-Y., Arain, G. A., \& Bhatti, Z. A. (2019). How does participation and browsing affect continuance intention in virtual communities? An integration of curiosity theory and subjective well-being. Behaviors \& Information Technology, 1-19. https://doi.org/10.1080/0144929x.2019.1685002

Faraj, S., \& Johnson, S. L. (2011). Network exchange patterns in online communities. Organization Science, 6(22), 1464-1480. https://doi.org/10.1287/orsc.1100.0600

Flynn, L. R., Gold Smith, R. E., \& Eastman, J. K. (1996). Opinion leaders et opinion seekers: two new measurement scales. Journal of the Academy of Marketing Science, 24(2), 137-147. https://doi.org/10.1177/0092070396242004

Francis, P., \& Dominique, P. (2008). Comment le web change le monde: l'alchimie des' Multitudes (p. 263). Paris: Pearson Village Mondial.

Ganley, D., Moser, C., \& Groenewegen, P. (2012). Categorizing behavior in online communities: A look into the world of cake bakers. System science (HICSS). 2012 45th Hawaii International Conference (pp. 3457-3466): IEEE. https://doi.org/10.1109/HICSS.2012.146

Goh, K. Y., Heng, C. S., \& Lin, Z. (2013). Social media bret community et consumer behavior: Quantifying the relative impact of user-et marketer-generated content. Information Systems Research, 24(1), 88-107. https://doi.org/10.1287/isre.1120.0469

Goyette, I., Ricard, L., Bergeron, J., \& Marticotte, F. (2010). E-WOM scale: Word-of-mouth measurement scale for e-services context. Canadian Journal of Administrative Science, 27(1), 5-23. https://doi.org/10.1002/cjas.129

Guo, L., Jacob, R., \& Wu, H. (2018). Who is responsible for Twitter's echo chamber problem? Evidence from 2016 U.S. election networks. Information, Communication \& Society, 23, 1-18. https://doi.org/10.1002/cjas.129

Hafiz, H. (2016). Helping as participation in an open online community: An exploratory study. Thesis, University of Warwick Centre for Education Studies.

Henderson, A., \& Bowley, R. (2010). Authentic dialogue? The role of "friendship" in a social media recruitment campaign. Journal of Communication Management, 14(3), 237-257. https://doi.org/10.1108/13632541011064517

Hennig-Thurau, T., Gwinner, K. P., Walsh, G., \& Gremler, D. D. (2004). Electronic word of mouth via consumer opinion platforms: What motivates consumers to articulate themselves on the Internet?. Journal of Interactive Marketing, 18(1), 38-52. https://doi.org/10.1002/dir.10073

Hur, M. H. (2006). Empowerment in terms of theoretical perspectives: exploring a typology of the process and components across disciplines. Journal of Community Psychology, 34(5), 523-540. https://doi.org/10.1002/jcop.20113

Jung, K. B., Kang, S.-W., \& Choi, S. B. (2020). Empowering leadership, risk-taking behavior, and employees' commitment to organizational change: the mediated moderating role of task complexity. Sustainability, 12(6), 2340. https://doi.org/10.3390/su12062340

Katz, J. (1998). Luring the Lurkers. Slashdot. Retrieved from http://slashdot.org

Khammash, M., \& Gareth, H. G. (2011). Arrivederci CIAO.com, Buongiorno Bing.com'Electronic word-of-mouth (e-WOM), antecedences et consequences. International Journal of Information Management, 31(1), 82-87. https://doi.org/10.1016/j.ijinfomgt.2010.10.005

Kim, A. J. (2000). Community building on the web: secret strategies for successful online communities. Peachpit Press, Berkeley.

Kollock, P., \& Smith, M. (1996). Managing the virtual commons: cooperation and conflict in computer communities. In S. Herring (Ed.), Computer-mediated communication: linguistic, social, and cross-cultural perspectives. John Benjamins, Amsterdam. https://doi.org/10.1075/pbns.39.10kol

Lave, J., \& Wenger, E. (1999). Legitimate peripheral participation. Learners, learning et assessment (pp. 83-89). London: The Open University.

Lee, Y.-W., Chen, F.-C., \& Jiang, H.-M. (2006). Lurking as participation: A community. 
Leshed, G. (2005). Posters, lurkers, and in between: a multidimensional model of online community participation patterns. Las Vegas: HCI International.

Leung, L. (2009). User-generated content on the Internet: an examination of gratifications, civic engagement and $\begin{array}{llllll}\text { psychological empowerment. New Media \& } & \text { Society, } & 11(8), & \text { 1327-1347. }\end{array}$ https://doi.org/10.1177/1461444809341264

Li, C., \& Bernoff, J. (2008). Groundswell: Winning in a world years old formed by social technologies. Boston, MA: Harvard Business School Press.

Li, F., \& Du, T. C. (2011). Who is talking? An ontology-based opinion leader identification framework for word-of-mouth marketing in online social blogs. Decision Support Systems, 51(1), 190-197. https://doi.org/10.1016/j.dss.2010.12.007

Li, Z. Ch. (2016). Psychological empowerment on social media: Who are the empowered users?. Public Relations Review, 42(1), 49-59.

Liang, T. P., Liu, C. C., \& Wu, C. H. (2008). Can social exchange theory explain individual knowledge-sharing behavior?. A meta-analysis. In Proceedings of the International Conference on Information Systems.

Liden, R. C., Sparrowe, R. T., \& Wayne, S. J. (1997). Leader-member exchange theory: The past and potential for the future. In G. R. Ferris (Ed.), Research in personnel and human resources management (pp. 47-119). Greenwich, CT: JAI Press.

Lin, M.-J. J., Hung, S.-W., \& Chen, C.-J. (2009). Fostering the determinants of knowledge sharing in professional virtual communities. Computers in Human Behavior, 25(4), 929939. https://doi.org/10.1016/j.chb.2009.03.008

Liu, C., \& Liu, F. (2020). The study of the effect of virtual brand community interaction on impulse buying: the moderating role of self-construal. Open Journal of Business and Management, 8, 414-427. https://doi.org/10.4236/ojbm.2020.82026

Markus, U. (2002). Characterizing the virtual community (5th ed.). SAP Design Guild.

Mason, B. (1999). Issuesin virtal ethnography in ethnographic Studies in Real and virtual environments.

McConnell, B., \& Huba, J. (2007). Citizen marketers: when people are the message. Chicago, IL: Kaplan Pub.

Menon, S. T. (1999). Psychological empowerment: definition, measurement, and validation. Canadian Journal of Behavioral Science, 31(3), 161. https://doi.org/10.1037/h0087084

Meyer, J. P., \& Allen, N. J. (1991). A three-component conceptualization of organizational commitment. Human Resource Management Review, 1(1), 61-89. https://doi.org/10.1016/1053-4822(91)90011-Z

Muntinga, D. G., Moorman, M., \& Smit, E. G. (2011). Introducing COBRAs: Exploring motivations for bret-related social media use. International Journal of Advertising, 30(1), 13-46. https://doi.org/10.2501/IJA-30-1-013-046

Nonnecke, B., \& Preece, J. (2000). Lurker demographics: Counting the silent. In Proceedings of the SIGCHI conference on Human factors in computing systems, ACM (pp. 73-80). https://doi.org/10.1145/332040.332409

Nonnecke, B., Preece, J. J., \& Etrews, D. (2004). What lurkers et posters think of each other. In Paper presented at the 37th Annual Hawaii International Conference on System Sciences. Los Alamitos, CA, USA. https://doi.org/10.1109/HICSS.2004.1265462

Paek, H.-J., \& Nelson, M. R. (2009). To buy or not to buy: Determinants of socially responsible consumer behavior and consumer reactions to cause-related and boycotting ads. Journal of Current Issues \& Research in Advertising, 31(2), 75-90. https://doi.org/10.1080/10641734.2009.10505267

Pagani, M., \& Mirabello, A. (2011). The influence of personal et social-interactive engagement in social TV web sites. International Journal of Electronic Commerce, 16(2), 41-68. https://doi.org/10.2753/JEC1086-4415160203

Powazek, D. M. (2002). Design for community: the art of connecting real people in virtual places. New Riders.

Sánchez-González, G., \& González-F, A. M. (2020). The Influence of Quality on e-WOM: A Digital Transformation in Hotel Management. Frontiers in Psychology.

Shao, G. (2009). Understanding the appeal of user-generated media: A uses et gratification perspective. Internet Research, 19(1), 7-25. https://doi.org/10.1108/10662240910927795 
Siebenhüner, B., \& Heinrichs, H. (2010). Knowledge and social learning for sustainable development. In M. Gross, \& H. Heinrichs (Eds.), Environmental sociology, European perspectives and interdisciplinary challenges (pp. 185-200). Dordrecht: Springer. https://doi.org/10.1007/978-90-481-8730-0_11

Speer, P. W. (2000). Intrapersonal and interactional empowerment: implications for theory. Journal of Community Psychology, 28(1), 51-61. https://doi.org/10.1002/(SICI)15206629(200001)28:1<51::AID-JCOP6>3.0.CO;2-6

Sproull, L., Conley, C., \& Moon, J. Y. (2005). Prosocial behavior on the net, the social net: Understanding human behavior in cyberspace (pp. 139-161).

Sun, T., You, S., Wu, G., \& Kuntaraporn, M. (2006). Online word-of-mouth (or mouse): an exploration of its antecedents et consequences. Journal of Computer Mediated Communication, 11(4). https://doi.org/10.1111/j.1083-6101.2006.00310.x

Swartz, A. (2006). Raw thought: Who writes Wikipedia. Blog article. Retrieved from http:/www.aaronsw.com/weblog/whowriteswikipedia

Valverde-B, J., María, A., Videla, C., \& Morales-C, M. (2020). Trends in educational research about e-learning: a systematic literature review (2009-2018). Sustainability, 12, 5153. https://doi.org/10.3390/su12125153

Vasic, N. K. M., \& Kaurin, T. (2019). The influence of online shopping determinants on customer satisfaction in the serbian market. Journal of Theoretical and Applied Electronic Commerce Research, 14(2), 70-89. https://doi.org/10.4067/s0718-18762019000200107

Wenger, E. (1998). Communities of Practice: Learning, Meaning, et Identity. Cambridge: Cambridge University Press. https://doi.org/10.1017/CBO9780511803932

Wenger, E. (2000). Communities of Practice et Social Learning Systems. Organization, 7(2), 225-246. https://doi.org/10.1177/135050840072002

Zhu, F., \& Zhang, X. Q. (2010). Impact of online consumer reviews on sales: the moderating role of product et consumer characteristics. Journal of Marketing, 74(2), 133-148. https://doi.org/10.1509/jm.74.2.133

\section{Appendix A}

Maintenance guide: Introducing the buying behavior of customer.

How do you usually prepare your purchase deed?

Do you search a product online before you go to the point of sale?

You prefer to find out about the characteristics of the product from sign sites, search engines (google, yahoo,) or from Facebook groups like "We ate for you", "We tested for you", "we travel for you"?

\section{Theme 1: Online interactions}

In this theme, we will analyze the behavior of the consumer within a virtual community, in order to know the degree of his involvement in the group (distinguish opinion leaders and lurkers)

What do you do when you visit Facebook groups?

Have you ever reacted with a "like" or "comment" on Facebook self-help groups? If so, in what situation? If not, why?

Are you influenced by the choices other members express in Facebook groups?

\section{Theme 2: The Virtual community}

In this theme, we first asked how the consumer can evaluate his position in the virtual community, then we try to find out how the consumer does he participates in a virtual community like "We ate for you" or "We tested for you" and how can he strengthen his position.

What social networking groups do you subscribe to?

What do you think it brings to be on these groups?

Have you ever shared your experience on social media?

Do you think you can influence other members' purchasing decisions when you share your experience with the product? 
Do you think that without this group, you would have had the chance to know certain products well? or to be able to claim and act?

\section{Theme 3: The Direct Experience}

In this theme, we try to understand the elements of satisfaction when the consumer contacts directly with the product. For this, we try to find years old wers to the questions below questions.

When you're in the point of sale, are you only interested in the product? or by the whole environment of the product in question? (Quality of service, atmosphere...)

Once in store, do you make a comparison between what you learned about the product through the sharing networks and your own experience?

\section{Theme 4: Customer Engagement}

In this theme, we try to understand how consumers, after their own experience of the product, behave within self-help networks. To do that, we try to find years old wers to these questions.

What would be your reaction, within a Facebook group, to a bad experience with a product or brand?

What would be your reaction, within a Facebook group, if you were satisfied?

What would be your reaction, within a Facebook group, if your own experience is significantly different from those expressed in comments posted by other members of the Facebook group?

\section{Appendix B}

\section{NVIVO Coding 12 of 14 Interviews}

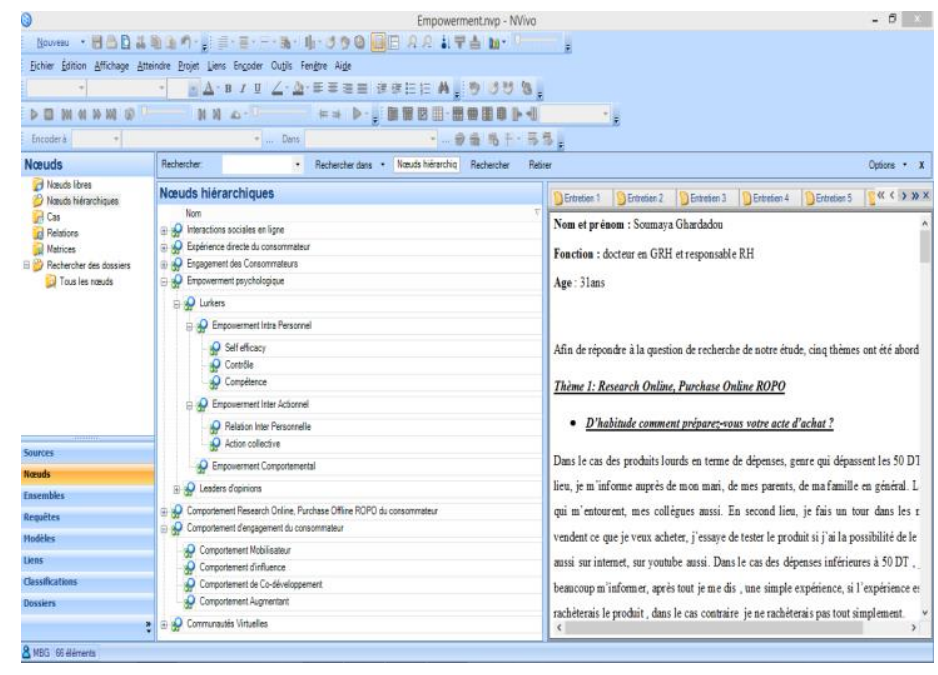




\section{Appendix C}

Table C1. The profile of interviewees

\begin{tabular}{|c|c|c|c|c|c|}
\hline Echantillon & Age & & $\operatorname{sex}$ & Function & $\begin{array}{l}\text { Time of the } \\
\text { Interview }\end{array}$ \\
\hline Interview $n^{\circ} 1$ & & years & Female & Marketing Manager bank & $35 \mathrm{mn}$ \\
\hline Interview $n^{\circ} 2$ & & years & Female & $\begin{array}{l}\text { Responsible follow-up trading pole } \\
\text { bank }\end{array}$ & $30 \mathrm{mn}$ \\
\hline Interview $\mathrm{n}^{\circ} 3$ & & years & Female & Responsible life insurance & $30 \mathrm{mn}$ \\
\hline Interview $\mathrm{n}^{\circ} 4$ & & years & Female & French Embassy & $25 \mathrm{~min}$ \\
\hline Interview $n^{\circ} 5$ & & years & Female & Charged back office bank & $40 \mathrm{mn}$ \\
\hline Interview $n^{\circ} 6$ & $\begin{array}{l}31 \\
\text { old }\end{array}$ & years & Male & Loaded Monetic bank & $25 \mathrm{mn}$ \\
\hline Interview $\mathrm{n}^{\circ} 7$ & & years & Male & Customer manager bank & $25 \mathrm{mn}$ \\
\hline Interview $\mathrm{n}^{\circ} 8$ & & years & Female & Doctoral student & $45 \mathrm{mn}$ \\
\hline Interview $n^{\circ} 9$ & & years & Female & Doctor and teacher & $40 \mathrm{mn}$ \\
\hline Interview $\mathrm{n}^{\circ} 10$ & & years & Male & $\begin{array}{l}\text { Chargé RH dyears old une société } \\
\text { d'informatique }\end{array}$ & $30 \mathrm{mn}$ \\
\hline Interview $n^{\circ} 11$ & & years & Male & $\begin{array}{l}\text { Responsable communication dyears old } \\
\text { une banque }\end{array}$ & $40 \mathrm{mn}$ \\
\hline Interview $\mathrm{n}^{\circ} 12$ & & years & Female & Human Resource Manager & $35 \mathrm{mn}$ \\
\hline 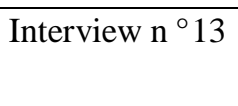 & $\begin{array}{l}38 \\
\text { old }\end{array}$ & years & Female & Professor on law & $45 \mathrm{mn}$ \\
\hline Interview $\mathrm{n}^{\circ} 14$ & $\begin{array}{l}41 \\
\text { old }\end{array}$ & years & Female & French Teacher & $40 \mathrm{mn}$ \\
\hline
\end{tabular}

\section{Copyrights}

Copyright for this article is retained by the author(s), with first publication rights granted to the journal.

This is an open-access article distributed under the terms and conditions of the Creative Commons Attribution license (http://creativecommons.org/licenses/by/4.0/). 